\title{
Variabilidade espacial de Planossolo e produtividade de soja em várzea sistematizada: análise geoestatística e análise de regressão
}

\author{
Spatial variability of a Planosol and soybean yield on a land-leveled paddy soil: geoestatistical \\ and regression analysis
}

\author{
José Miguel Reichert ${ }^{\mathrm{I}^{*}}$ Thelmo Araújo Dariva ${ }^{\mathrm{II}}$ Dalvan José Reinert ${ }^{1}$ \\ Vanderlei Rodrigues da Silva ${ }^{\text {III }}$
}

\section{RESUMO}

\begin{abstract}
Atributos do solo e da planta, espacialmente definidos, contribuem para o planejamento de lavouras comerciais e a locação de experimentos. O presente trabalho teve por objetivo estudar a variabilidade espacial de alguns atributos físicos e químicos do solo e sua relação com a produtividade de soja em várzea sistematizada. $O$ experimento foi realizado no ano agrícola de 2000, na área experimental do Departamento de Solos da Universidade Federal de Santa Maria, Santa Maria, RS, em um Planossolo Hidromórfico distrófico típico. Uma área de 160 × 88m foi amostrada em grade de $8 \times 8 m$, totalizando 240 pontos. A produtividade e a altura de plantas de soja e atributos químicos e físicos do solo superficial $(0$ a $0,15 \mathrm{~m})$ e subsuperficial $(0,15$ a $0,30 \mathrm{~m})$ foram avaliadas. Para os atributos edáficos da camada de solo de 0 $0,15 \mathrm{~m}$ de profundidade, que apresentaram correlação com os atributos de planta, usaram-se técnicas de geoestatística, sendo a dependência espacial dos atributos avaliada por semivariogramas escalonados. Com exceção da densidade de partículas e do grau de floculação, todas as demais variáveis apresentaram dependência espacial de moderada $(0,64$ a 0,75$)$ a forte $(>0,75)$. A variabilidade espacial dos atributos físicos $e$ químicos do solo afetou a produtividade de soja. Os atributos do solo analisados foram divididos, quanto ao alcance e ao modelo de semivariograma, em dois grupos: um grupo com modelo exponencial e alcance menor que $40 \mathrm{~m}$ e outro com modelo gaussiano e alcance menor que $67 \mathrm{~m}$. A variabilidade espacial da produtividade de soja foi descrita pelo modelo gaussiano com alcance menor que $45 \mathrm{~m}$.
\end{abstract}

Palavras-chave: planossolo, terras baixas, geostatística, nivelamento do solo.

\section{ABSTRACT}

Spatially-defined soil and plant properties contribute to better planning of experiments and commercial fields. This research had as objective the study of spatial variability of some physical and chemical properties of the soil and their relationship with soybean productivity. The experiment was conducted in the agricultural year of 2000, at the Federal University of Santa Maria, RS, Brazil, on land-leveled paddy soil. An area of $160 \times 88 \mathrm{~m}$ was sampled at an interval of $8 \times$ $8 m$, resulting in 240 sampling points. The plant properties studied were soybean yield and plant height. Several chemical and physical properties of the topsoil $(0$ to $0.15 \mathrm{~m})$ and subsoil $(0.15$ to $0.30 \mathrm{~m})$ were determined. Geostatistical analysis was done only for the soil layer that presented correlation with the plant properties $(0-0.15 \mathrm{~m})$, and the space dependence of the attributes was evaluated by scaled semivariograms. Except for soybean production, particle density and flocculation degree, all soil properties presented moderate (0.64 to 0.75$)$ to strong $(>0.75)$ space dependence. The production of soybean was influenced by space variability of the analyzed soil properties. The spatial variability of the soil physical and chemical properties in land-leveled paddy soil affected the production of soybean. The properties were classified in two different categories, based on semivariogram model and range: (i) exponential model and range smaller than $40 \mathrm{~m}$ and (ii) gaussian model and range smaller than $67 \mathrm{~m}$. A gaussian model with range smaller than $45 \mathrm{~m}$ described the spatial variation of soybean yeild.

Key words: Planosols, lowlands, geoestatistics, soil leveling.

\section{INTRODUÇÃO}

A heterogeneidade dos atributos do solo em lavouras é comum, afetando diferenciadamente o desenvolvimento e a produtividade das culturas. Essa variabilidade do solo, muitas vezes, não é puramente aleatória, mas apresenta dependência espacial

\footnotetext{
'Departamento de Solos, Centro de Ciências Rurais (CCR), Universidade Federal de Santa Maria (UFSM), 97105-900, Santa Maria, RS, Brasil. E-mail: reichert@smail.ufsm.br.*Autor para correspondência.

"Instituto Brasileiro de Geografia e Estatística (IBGE), Belém, PA, Brasil.

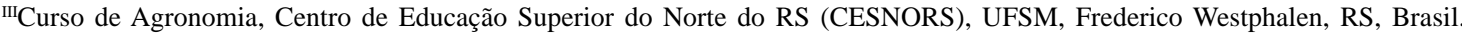


ocasionada por diversos fatores, como indicado em vários trabalhos (ZHANG et al., 1992; VIEIRA, 1995; VIEIRA, 1997; COUTO et al., 2000; SILVEIRA et al., 2000). Essa variabilidade é resultante do processo natural de formação do solo e variações no relevo (DA SILVA et al., 1989; COUTO et al., 2000; SOUZA et al., 2004; CAMPOS et al., 2007), da erosão (ALBUQUERQUE et al., 1996; SALVIANO et al., 1998; SOUZA et al., 2003), do manejo e das práticas agrícolas utilizadas (PAZ-GONZÁLEZ et al., 2000; TREVISAN, 2005; CORÁ et al., 2006), da sistematização de solos (DARIVA, 2001) e da construção de solos com em áreas de mineração (GUADAGNIM, 2002; LEITZKE, 2002), agindo em diferentes escalas no espaço e no tempo (JAYNES \& COLVIN, 1997).

O cultivo do solo altera seus atributos iniciais, por meio de práticas agrícolas usuais como calagem, adubação e outras práticas de manejo (SANTOS \& VASCONCELOS, 1987; KLEPKER \& ANGHINONI, 1995; COUTO et al., 1997; SCHLINDWEIN \& ANGHINONI, 2000; PAZGONZÁLEZ et al., 2000; CORÁ \& BERALDO, 2006). Da mesma forma, o desenvolvimento e a produção das culturas apresentam variabilidade espacial (ABREU et al., 2003; SILVA et al., 2004) de acordo com o comportamento das propriedades físicas ou químicas do solo mais limitantes ao desenvolvimento da planta, sendo fatores importantes de análise para o planejamento e a avaliação de experimentos e de lavouras comerciais. A utilização de delineamentos experimentais baseados na repetição e na casualização exige que as observações sejam independentes umas das outras e que as parcelas experimentais sejam uniformes quanto às variáveis estudadas, o que nem sempre ocorre em parcelas no campo.

A sistematização de terras baixas (solos de várzea) consiste no nivelamento da superfície do solo num plano pré-definido, utilizando-se o solo das cotas mais elevadas (originando áreas de corte) para aterrar os solos de cotas inferiores (originando áreas de aterro) (IRGA, 1996). A grande mobilização produz mistura de horizontes e altera as condições naturais do solo, afetando vários de seus atributos (PREVE \& MARTENS, 1990; NUNES et al., 2002). Além disso, a produtividade de cultivos é afetada pela exposição da subsuperfície do solo com menor concentração de nutrientes e de matéria orgânica (PREVE \& MARTENS, 1990).

O objetivo deste trabalho foi estudar a variabilidade espacial de alguns atributos físicos e químicos de um Planossolo nivelado e sua relação com a produtividade de soja.

\section{MATERIAL E MÉTODOS}

Caracterização da área e condução do experimento O trabalho foi desenvolvido num solo de várzea, localizada na Área Experimental do Departamento de Solos da Universidade Federal de Santa Maria (UFSM), em Santa Maria, RS, na região fisiográfica da Depressão Central do Rio Grande do Sul. O solo é classificado como Planossolo Hidromórfico distrófico típico (EMBRAPA, 1999) e o clima da região é do tipo subtropical úmido sem estiagens (Cfa2), de acordo com a classificação climática de Köeppen (MORENO, 1961).

A área em estudo foi sistematizada em 1995, realizando-se cortes e aterros da área para nivelar o terreno. Posteriormente, foram realizadas três safras com arroz irrigado, sendo utilizado o preparo convencional. No presente trabalho foram usados dados da safra 1999/ 2000 quando foi implantada a cultura de soja (Glycine $\max$ L. Merrill), utilizando-se preparo convencional, envolvendo uma aração que atingiu a profundidade de 0,30 m e duas gradagens. Essas operações foram realizadas nos meses de novembro e dezembro.

A semeadura da soja foi realizada na primeira quinzena de dezembro de 1999, com espaçamento entre linhas de $0,45 \mathrm{~m}$, semeando-se 27 sementes por metro linear da cultivar "FT-Abyara" e adubação de base de $200 \mathrm{~kg} \mathrm{ha}^{-1}$ da fórmula 0-20-20.

A área de $160 \mathrm{~m}$ por $88 \mathrm{~m}$ foi demarcada em uma malha fixa com espaçamento regular de 8 metros, onde se amostrou o solo nas profundidades de $0-0,15 \mathrm{~m}$ e 0,15-0,30m, por ocasião da floração das plantas de soja, totalizando 480 amostras. A distância entre os pontos de coleta de amostras foi de $8 \mathrm{~m}$ para os atributos químicos e densidade de partículas, e $16 \mathrm{~m}$ para os demais atributos mencionados a seguir.

Cada amostra foi composta por três subamostras, as quais foram coletadas com trado calador a cada 0,30 m na entrelinha de semeadura. As amostras foram levadas ao laboratório, secas em estufa com circulação forçada de ar a $60^{\circ} \mathrm{C}$, moídas em moinho de martelos e peneiradas em tamiz de $2 \mathrm{~mm}$, para posterior análise.

As amostras foram analisadas para $\mathrm{pH}$ em KCl 1 mol L $^{-1}$ (EMBRAPA, 1997), pH em água (relação 1:1), teor de matéria orgânica, teor de fósforo disponível, potássio disponível, cálcio trocável, magnésio trocável, manganês trocável, sódio trocável e alumínio trocável, utilizando-se técnicas descritas por TEDESCO et al. (1995).

As determinações físicas realizadas foram densidade de partículas, pelo método do balão volumétrico (EMBRAPA, 1997), e granulometria do solo, 
pelo método da pipeta (DAY, 1965), determinando-se as frações areia total, areia grossa, areia fina, silte, argila total e argila natural, e calculando-se o grau de floculação de argila. A resistência à penetração foi determinada no dia 03 de janeiro de 2001 com o auxílio de penetrógrafo de cone, segundo metodologia descrita por BRADFORD (1986). Foram realizadas três avaliações para cada ponto, distanciadas em torno de 0,30m uma da outra, sendo realizadas em todos os pontos da área. A resistência à penetração foi avaliada na camada de $0,06-0,075 \mathrm{~m}$.

A altura da planta foi determinada por ocasião do pleno florescimento, levando-se em consideração a distância média do solo até o ponto de crescimento da haste principal, utilizando-se três plantas por ponto amostral. A produtividade da soja foi determinada por ocasião da colheita.

\section{Análise estatística}

Análises de correlação e de regressão simples e múltipla foram realizadas entre produtividade e altura de plantas de soja e os atributos químicos e físicos do solo. Na análise de regressão múltipla, os valores faltantes de variáveis foram preenchidos por interpolação simples, e para os atributos que foram coletados em pontos com espaçamento de $16 \mathrm{~m}$ utilizouse a técnica da krigagem para interpolação e determinação dos locais não amostrados. Com a finalidade de identificar quais propriedades de solo foram mais determinantes da expressão na produção de soja na área estudada, efetuou-se a análise de regressão múltipla pela técnica stepwise (SAS, 1996).

Na análise da variabilidade espacial de atributos do solo, utilizaram-se somente as variáveis químicas e físicas na profundidade de 0 a $0,15 \mathrm{~m}$, ou seja, aquelas que apresentaram correlação (coeficiente de correlação significativo) com a produtividade de soja.

A análise geoestatística foi utilizada para avaliar a dependência espacial dos atributos do solo e da planta, sendo realizada pela construção de semivariogramas, obtidos a partir do cálculo das semivariâncias pela equação 1 (JOURNEL \& HUIJBEREGTS, 1989):

$$
\gamma(\mathrm{h})=\frac{1}{2 \mathrm{~N}(\mathrm{~h})} \sum_{\mathrm{i}=1}^{\mathrm{N}(\mathrm{h})}\left[\mathrm{Z}\left(\mathrm{x}_{\mathrm{i}}\right)-\mathrm{Z}\left(\mathrm{x}_{\mathrm{i}}+\mathrm{h}\right)\right]^{2}
$$

onde: $\tilde{a}(\mathrm{~h})$ = semivariância em função da distância; $\mathrm{h}=$ distância de separação das amostras; $\mathrm{N}(\mathrm{h})=$ =número de pares de valores medidos; $\mathrm{Z}\left(\mathrm{x}_{\mathrm{i}}\right)=$ valor da variável medida na posição $\mathrm{xi} ; \mathrm{Z}\left(\mathrm{x}_{\mathrm{i}+\mathrm{h}}\right)=$ valor da variável na posição $x_{i+h}$. Os procedimentos de cálculo da semivariância e o ajuste de equações foram realizados com o auxílio do programa computacional GS+ versão 5.1.1 (Gs ${ }^{+}$(GAMMADESIGN SOFTWARE, 2001).

As variáveis altura de plantas, $\mathrm{pH}$ em água, pH em KCl, alumínio trocável, saturação por alumínio, argila total e grau de floculação das argilas, os quais apresentaram falta de estacionaridade pela presença de tendências, foram submetidas a refinamento dos dados pela mediana, utilizando-se os resíduos nos passos subseqüentes. Essa técnica consiste em, seqüencialmente, (i) dispor os dados de acordo com sua posição na malha amostral; (ii) calcular a mediana de cada linha e coluna; (iii) subtrair de cada valor amostrado o valor da mediana da linha e da coluna em que se encontra; e (iv) adicionar, a cada valor amostrado, o valor da mediana de todo o conjunto de dados. Os valores remanescentes no quadro resultante são os resíduos. Tal procedimento é repetido até que a convergência seja observada.

Os semivariogramas experimentais foram ajustados a modelos matemáticos, estimando-se os parâmetros efeito pepita, alcance e patamar. Para a escolha do modelo de semivariograma, aplicou-se a técnica de validação cruzada (método Jack-knife) e como critério de decisão considerou-se o erro reduzido (RIBEIROJUNIOR, 1995).

\section{RESULTADOS E DISCUSSÃO}

Os atributos físicos e químicos do solo, cujos valores médios são apresentados na tabela 1 , que mais estiveram associados à produtividade (Tabela 2) foram o pH em água e em $\mathrm{KCl}$, a saturação por alumínio e alumínio e magnésio trocáveis ( $r>0,63)$. Em relação à altura de plantas de soja, os atributos foram o pH em água e em KCl e alumínio e manganês trocáveis $(\mathrm{r}>0,50)$. Plantas mais altas foram mais produtivas $(r=0,550)$. Houve correlação altamente significativa $(\mathrm{P}<0,0001)$ e positiva entre a produtividade de soja e as variáveis $\mathrm{pH}$ em água e em $\mathrm{KCl}$, teores de cálcio e magnésio trocáveis, soma de bases (SB), capacidade de troca catiônica (CTC) e argila natural. Em contraste, houve correlação negativa entre a produtividade e a altura das plantas de soja com os atributos alumínio, manganês e sódio trocáveis, saturação por alumínio, argila total e grau de floculação.

Praticamente todos os atributos de solo descritos anteriormente são influenciados pelo $\mathrm{pH}$. O $\mathrm{pH}$ correlaciona-se positivamente com os valores de $\mathrm{P}$, Ca, Mg, K, soma e saturação por bases e CTC e negativamente com a saturação de $\mathrm{Al}$ (ABREU Jr et al., 2003). O efeito detrimental da acidez do solo no crescimento e na produtividade de plantas depende da atividade dos íons $\mathrm{H}^{+}$e $\mathrm{Al}^{3+}$ na solução do solo, o que 
Tabela 1 - Valor médio para atributos físicos e químicos do solo em duas profundidades.

\begin{tabular}{|c|c|c|}
\hline \multirow{2}{*}{ Atributo } & \multicolumn{2}{|c|}{---------------Profundidade (m)--------------- } \\
\hline & $0-0,15$ & $0,15-0,30$ \\
\hline pH em água $1: 1$ & 4,91 & 4,77 \\
\hline pH em KCl & 3,92 & 3,88 \\
\hline Al trocável $\left(\mathrm{cmol}_{\mathrm{C}} \mathrm{kg}^{-1}\right)$ & 1,48 & 1,80 \\
\hline Ca trocável $\left(\mathrm{cmol}_{\mathrm{c}} \mathrm{kg}^{-1}\right)$ & 3,72 & 3,47 \\
\hline Mg trocável $\left(\mathrm{cmol}_{\mathrm{c}} \mathrm{kg}^{-1}\right)$ & 1,45 & 1,29 \\
\hline Mn trocável (mg kg-1) & 43,49 & 45,09 \\
\hline Matéria orgânica (\%) & 1,62 & 1,35 \\
\hline Na trocável (mg kg $\left.{ }^{-1}\right)$ & 18,21 & 21,79 \\
\hline K trocável (mg kg-1) & 51,25 & 25,39 \\
\hline P disponível (mg kg-1) & 8,49 & 5,27 \\
\hline Soma de bases $\left(\mathrm{cmol}_{\mathrm{c}} \mathrm{kg}^{-1}\right)$ & 5,41 & 4,89 \\
\hline Capacidade de troca de cátions efetiva $\left(\mathrm{cmol}_{\mathrm{c}} \mathrm{kg}^{-1}\right)$ & 6,88 & 6,70 \\
\hline Saturação por $\mathrm{Al}(\%)$ & 23,04 & 28,24 \\
\hline Areia total $\left(\mathrm{g} \mathrm{kg}^{-1}\right)$ & 368,00 & 377,29 \\
\hline Argila natural $\left(\mathrm{g} \mathrm{kg}^{-1}\right)$ & 93,74 & 104,92 \\
\hline Grau de floculação (\%) & 46,80 & 51,71 \\
\hline Areia grossa $\left(\mathrm{g} \mathrm{kg}^{-1}\right)$ & 124,72 & 124,10 \\
\hline Areia fina $\left(\mathrm{g} \mathrm{kg}^{-1}\right)$ & 244,27 & 253,15 \\
\hline Argila $\left(\mathrm{g} \mathrm{kg}^{-1}\right)$ & 188,26 & 219,27 \\
\hline Silte $\left(\mathrm{g} \mathrm{kg}^{-1}\right)$ & 444,38 & 409,15 \\
\hline Densidade de partículas $\left(\mathrm{Mg} \mathrm{m}^{-3}\right)$ & 2,55 & 2,55 \\
\hline
\end{tabular}

está relacionado com a atividade de teores de cálcio $\left(\mathrm{Ca}^{2+}\right)$, magnésio $\left(\mathrm{Mg}^{2+}\right)$ e potássio $\left(\mathrm{K}^{+}\right)$trocáveis e de matéria orgânica do solo (PAVAN, 1983). Com a neutralização de parte da acidez, as cargas negativas são liberadas no complexo de troca e ocupadas por
$\mathrm{Ca}^{2+}, \mathrm{Mg}^{2+}$ e K , aumentando a fertilidade do solo e a produção agrícola. Com o aumento das cargas negativas e a neutralização do alumínio trocável, aumenta a dispersão de argilas (argila natural) e diminui o grau de floculação. Por isso, neste estudo, a

Tabela 2 - Coeficiente de correlação entre produtividade e altura de plantas de soja com alguns atributos físicos e químicos do solo, na profundidade de 0 a $0,15 \mathrm{~m}$.

\begin{tabular}{|c|c|c|}
\hline \multirow{2}{*}{ Atributo } & \multicolumn{2}{|c|}{----------Coeficiente de correlação (r, P < 0,0001)---------- } \\
\hline & Produtividade $\left(\mathrm{kg} \mathrm{ha}^{-1}\right)$ & Altura de planta (m) \\
\hline pH em água 1:1 & 0,697 & 0,556 \\
\hline pH em KCl & 0,692 & 0,508 \\
\hline Al trocável $\left(\mathrm{cmol}_{\mathrm{c}} \mathrm{kg}^{-1}\right)$ & $-0,674$ & $-0,545$ \\
\hline Ca trocável $\left(\mathrm{cmol}_{\mathrm{C}} \mathrm{kg}^{-1}\right)$ & 0,551 & NS * \\
\hline Mg trocável $\left(\mathrm{cmol}_{\mathrm{c}} \mathrm{kg}^{-1}\right)$ & 0,638 & 0,300 \\
\hline Mn trocável (mg kg $\left.{ }^{-1}\right)$ & $-0,413$ & $-0,610$ \\
\hline Na trocável $\left(\mathrm{mg} \mathrm{kg}^{-1}\right)$ & $-0,274$ & $-0,463$ \\
\hline Soma de bases $\left(\mathrm{cmol}_{\mathrm{c}} \mathrm{kg}^{-1}\right)$ & 0,585 & 0,176 \\
\hline Capacidade de troca de cátions efetiva $\left(\mathrm{cmol}_{\mathrm{c}} \mathrm{kg}^{-1}\right)$ & 0,383 & NS \\
\hline Saturação por Al (\%) & $-0,684$ & $-0,420$ \\
\hline Argila natural $\left(\mathrm{g} \mathrm{kg}^{-1}\right)$ & 0,472 & NS \\
\hline Argila total $\left(\mathrm{g} \mathrm{kg}^{-1}\right)$ & $-0,276$ & $-0,463$ \\
\hline Grau de floculação (\%) & $-0,564$ & $-0,480$ \\
\hline Altura de planta (m) & 0,550 & \\
\hline
\end{tabular}

*NS = não significativo.

Ciência Rural, v.38, n.4, jul, 2008. 
correlação negativa da produtividade e a altura de planta com o grau de floculação deve-se ao efeito indireto da melhoria do ambiente químico do solo e não ao efeito físico do ambiente mais disperso das partículas de solo.

Na análise de regressão múltipla, o modelo (equação 2) explicou aproximadamente 65\% da variância observada nos dados de produtividade de soja. Nesse modelo de regressão, o pH em água e o índice de saturação por alumínio na camada mais superficial do solo $(0-0,15 \mathrm{~m})$ apresentaram a maior contribuição ( $\mathrm{r}^{2}$ parcial, dados não-mostrados) na predição de produtividade de soja.

Produtividade $=-0,5481+0,7565(\mathrm{pH}$ em água $0-0,15 \mathrm{~m})$ -0,0230(Saturação por alumínio 0-0,15m)+ 0,0002(Resistência à penetração 0,06-0,075m)0,0083(Areia grossa 0,15 a 0,30m) - 0,0146(Manganês $0-0,15 \mathrm{~m}$ ) + 0,0031(Areia fina 0,15-0,30m) - 0,0056(Argila natural 0,15 a 0,30m) + 0,0988(CTC 0-0,15m) (eq. 2)

Com exceção da densidade de partículas e do grau de floculação que apresentaram efeito pepita puro, a análise dos semivariogramas mostrou a existência de dependência espacial em todas os atributos estudados (Tabela 3). As semivariâncias para os atributos fósforo e potássio disponíveis, altura de plantas, pH em água, pH em KCl e argila total ajustaramse melhor ao modelo exponencial; e para o teor de areia grossa, modelo esférico e os demais atributos as semivariâncias ajustaram-se melhor ao modelo gaussiano (Tabela 3).

Grande parte dos trabalhos em geoestatística utiliza, para o ajuste do semivariograma dos atributos do solo, o modelo esférico (CAMBARDELLA et al., 1994; BOYER et al., 1996; ALBUQUERQUE et al., 1996; TSEGAYE \& HILL, 1998; PAZ-GONZÁLEZ et al., 2000). Contudo, o tipo de modelo pode depender do atributo e da camada de solo analisada. Nesse sentido, K, pH, Ca, H+Al, CTC e saturação por bases na camada 0-0,2m ajustaram-se melhor ao modelo esférico e $\mathrm{P}$ e $\mathrm{Mg}$ a um modelo exponencial. Na camada $0,6-0,8 \mathrm{~m}$, somente $\mathrm{K}, \mathrm{Ca}, \mathrm{H}+\mathrm{Al}$ e CTC ajustaram-se melhor ao modelo esférico, enquanto que $\mathrm{pH}, \mathrm{P}, \mathrm{Mg}$ e saturação por bases ajustaram-se ao modelo exponencial. Neste trabalho, porém, sempre que possível, utilizou-se o modelo gaussiano, pois ele apresentou praticamente as mesmas estimativas dos parâmetros estatísticos do modelo esférico, diferindo mais intensamente apenas quanto ao parâmetro efeito pepita.

O efeito pepita revela a descontinuidade do semivariograma em distâncias menores que as

Tabela 3 - Modelo, valores do efeito pepita $\left(C_{0}\right)$, patamar $\left(C_{o}+C_{1}\right)$, alcance (a), relação efeito pepita/patamar (REP), coeficiente de determinação $\left(\mathrm{r}^{2}\right)$ e dependência espacial (DE) para alguns atributos de planta e de solo na profundidade de 0 a $0,15 \mathrm{~m}$.

\begin{tabular}{|c|c|c|c|c|c|c|c|}
\hline Atributo & Modelo & $\mathrm{C}_{0}$ & $\mathrm{C}_{0}+\mathrm{C}_{1}$ & $\mathrm{a}(\mathrm{m})$ & REP & $r^{2}$ & $\mathrm{DE}$ \\
\hline Produtividade $\left(\mathrm{Mg} \mathrm{ha}^{-1}\right)$ & Gaussiano & 0,338 & 1,157 & 44,4 & 0,708 & 0,99 & Moderada \\
\hline Altura de planta (m) & Exponencial & 0,003 & 0,011 & 11,38 & 0,659 & 0,89 & Moderada \\
\hline pH em água 1:1 & Exponencial & 0,012 & 0,034 & 10,18 & 0,635 & 0,91 & Moderada \\
\hline $\mathrm{pH} \mathrm{KCl}$ & Exponencial & 0,007 & 0,031 & 9,40 & 0,761 & 0,95 & Forte \\
\hline $\mathrm{Al}\left(\mathrm{cmol}_{\mathrm{C}} \mathrm{kg}^{-1}\right)$ & Exponencial & 0,035 & 0,079 & 16,0 & 0,559 & 0,96 & Moderada \\
\hline $\mathrm{Ca}\left(\mathrm{cmol}_{\mathrm{C}} \mathrm{kg}^{-1}\right)^{\mathrm{rq}}$ & Gaussiano & 0,022 & 0,128 & 49,8 & 0,828 & 0,99 & Forte \\
\hline $\operatorname{Mg}\left(\mathrm{cmol}_{\mathrm{c}} \mathrm{kg}^{-1}\right)$ & Gaussiano & 0,087 & 0,740 & 66,5 & 0,882 & 1,00 & Forte \\
\hline $\operatorname{Mn}\left(\mathrm{mg} \mathrm{kg}^{-1}\right)$ & Gaussiano & 76,100 & 247,500 & 23,6 & 0,693 & 0,99 & Moderada \\
\hline Matéria orgânica (\%) & Gaussiano & 0,038 & 0,181 & 49,3 & 0,792 & 0,99 & Forte \\
\hline $\mathrm{Na}\left(\mathrm{mg} \mathrm{kg}^{-1}\right)$ & Gaussiano & 8,930 & 27,450 & 24,0 & 0,675 & 0,99 & Moderada \\
\hline $\mathrm{K}\left(\mathrm{mg} \mathrm{kg}{ }^{-1}\right)$ & Exponencial & 0,008 & 0,022 & 18,0 & 0,640 & 0,96 & Moderada \\
\hline $\mathrm{P}\left(\mathrm{mg} \mathrm{kg}^{-1}\right)$ & Exponencial & 0,004 & 0,024 & 18,5 & 0,799 & 0,98 & Forte \\
\hline Saturação de bases (\%) & Gaussiano & 0,172 & 1,267 & 52,2 & 0,864 & 0,97 & Forte \\
\hline CTC efetiva $\left(\mathrm{cmol}_{\mathrm{C}} \mathrm{kg}^{-1}\right)$ & Gaussiano & 0,147 & 0,554 & 46,2 & 0,735 & 0,99 & Moderada \\
\hline Saturação por Al (\%) & Exponencial & 12,820 & 44,10 & 15,4 & 0,709 & 0,98 & Moderada \\
\hline Argila natural $\left(\mathrm{g} \mathrm{kg}^{-1}\right)^{\mathrm{rq}}$ & Gaussiano & 1,476 & 4,524 & 52,6 & 0,674 & 0,97 & Moderada \\
\hline Areia total $\left(\mathrm{g} \mathrm{kg}^{-1}\right)^{\ln }$ & Gaussiano & 0,830 & 4,638 & 47,2 & 0,821 & 0,98 & Forte \\
\hline Areia grossa ( $\left.\mathrm{g} \mathrm{kg}^{-1}\right)$ & Gaussiano & 216,000 & 1630,00 & 40,6 & 0,867 & 0,98 & Forte \\
\hline Areia fina $\left(\mathrm{g} \mathrm{kg}^{-1}\right)$ & Gaussiano & 695,000 & 2584,00 & 43,1 & 0,731 & 0,99 & Moderada \\
\hline Argila total ( $\left.\mathrm{g} \mathrm{kg}^{-1}\right)$ & Exponencial & 879,000 & 1907,00 & 38,6 & 0,539 & 0,92 & Moderada \\
\hline Silte $\left(\mathrm{g} \mathrm{kg}^{-1}\right)$ & Gaussiano & 1910,000 & 5530,00 & 37,1 & 0,655 & 0,99 & Moderada \\
\hline
\end{tabular}

rq = dados com transformação raiz quadrada; ln = dados com transformação logarítmica 
amostradas (VIEIRA, 2000). Trata-se da variabilidade não explicada pelo modelo, devido a erros de medida e/ ou microvariações não detectadas. A proporção de variação desse valor para o patamar do modelo é um indicativo da variação ao acaso de um ponto para outro, sendo esse critério adotado por CAMBARDELLA et al. (1994) para avaliar o grau de dependência espacial da variável.

Neste estudo, utilizou-se uma forma modificada da classificação de CAMBARDELLA et al. (1994), calculando-se a proporção de variação em função do espaço, ou seja, a variabilidade dependente do espaço (ALBUQUERQUE et al., 1996). Foram sendo considerados de dependência espacial forte os semivariogramas que têm uma variação dependente do espaço proporcionalmente superior a 0,75 do patamar, de dependência espacial moderada quando a variação dependente do espaço está proporcionalmente entre 0,75 e 0,25 do patamar e de dependência espacial fraca quando a variação dependente do espaço for proporcionalmente inferior a 0,25 do patamar.

Nesse contexto, a produtividade e a altura de plantas de soja apresentaram dependência espacial moderada (Tabela 3), reflexo da combinação dos atributos de solo, tendo em vista a forte correlação que os atributos de planta apresentaram com os atributos de solo.

Dos atributos químicos estudados, somente pH em água, manganês e sódio trocáveis, potássio disponível e capacidade de troca de cátions apresentaram dependência espacial moderada. Todas as demais variáveis químicas apresentaram forte dependência espacial. A capacidade de troca de cátions classificou-se como moderada em função de ser um reflexo da combinação das variâncias dos teores de cálcio, de magnésio, de sódio e de alumínio trocáveis e de potássio disponível, os quais variam de forma diferente em função da distância. As frações granulométricas areia total e areia grossa apresentaram forte dependência espacial, enquanto as demais frações apresentaram dependência espacial moderada (Tabela 3). Isso pode ser resultado da sistematização, a qual, ao remover parte da camada superior do solo em alguns locais, favoreceu o aparecimento de camadas com granulometria diferente, promovendo um aumento na variância, enquanto o alcance torna-se função da distância entre os cortes e aterros. A dependência moderada a forte deve-se, provavelmente, à pequena distância entre pontos amostrais. Valores mais altos de $\mathrm{C}_{0} /\left(\mathrm{C}_{0}+\mathrm{C}_{1}\right)$, equivalentes à dependência espacial forte, podem indicar que o solo possui uma variabilidade não amostrada, sendo que uma amostragem mais intensa pode revelar dependência espacial mais pronunciada.
Outro parâmetro importante na análise de semivariogramas é o alcance de dependência espacial, o qual marca a distância limite na qual um ponto amostral apresenta influência em outro ponto, ou seja, a distância máxima que uma variável está correlacionada espacialmente. Distâncias iguais as do alcance indicam que todos os vizinhos situados dentro de um círculo com esse raio podem ser usados na estimativa de valores em espaçamento mais próximos (VIEIRA \& LOMBARDI NETO, 1995) e, para a utilização da estatística clássica, deve-se utilizar determinações com espaçamentos maiores que o alcance, em que as determinações passam a ter distribuição aleatória, comportando-se como se fossem independentes entre si.

O alcance pode ser separado em dois grupos distintos (Tabela 3). O primeiro grupo sendo representado pelos atributos com semivariograma gaussiano e alcance menor que $67 \mathrm{~m}$, sendo eles produtividade de soja, cálcio, magnésio, manganês e sódio trocáveis, matéria orgânica, índice de saturação de bases, capacidade de troca de cátions efetiva, argila natural, areia total, areia grossa, areia fina e silte. $\mathrm{O}$ segundo grupo foi composto pelos atributos com semivariograma exponencial com alcance menor que 40m, sendo eles alumínio trocável, índice de saturação por alumínio, argila total, altura das plantas, $\mathrm{pH}$ em água, $\mathrm{pH}$ em $\mathrm{KCl}$ e teores de fósforo e potássio disponíveis.

O primeiro grupo, com alcance menor que $67 \mathrm{~m}$ e modelo gaussiano, foi fortemente influenciado pelos teores de areia total e silte, que apresentaram relação altamente significativa com o teor de matéria orgânica $\left(\mathrm{r}=-0,58^{* * *} \mathrm{r}=0,46^{* * *}\right.$, respectivamente) e esta última com a CTC efetiva $\left(\mathrm{r}=0,57^{* * *}\right)$. Esse comportamento deve-se ao processo de sistematização, que, ao remover camadas superficiais do solo, deve ter exposto e, em alguns casos, até removido o horizonte E, o que faz com que locais com maior teor de areia e menor de silte (MATTIAS, 1996) apresentem pouca matéria orgânica.

O segundo grupo, com alcance inferior a $40 \mathrm{~m}$ e modelo exponencial, está intimamente relacionado com o teor de alumínio trocável, o qual mantém uma forte correlação com as demais variáveis de solo do grupo, com coeficientes de correlação superiores a 0,69 ( $\mathrm{P}<0,0001)$, com exceção do teor de argila total, que se deve a fatores de formação do solo e do processo de sistematização da área.

\section{CONCLUSÕES}

A sistematização causou variabilidade espacial nos atributos de solo, refletindo-se na 
produtividade de soja. Na análise de regressão múltipla, $65 \%$ da variação na produtividade foi atribuída à variação nos atributos químicos: $\mathrm{pH}$ em água, saturação por alumínio, manganês trocável e capacidade de troca de cátions, e físicos: resistência à penetração, areias grossa e fina e argila natural. A densidade de partículas e o grau de floculação não apresentaram dependência espacial detectável com o espaçamento amostral utilizado, enquanto as demais variáveis analisadas apresentaram moderada a forte dependência espacial.Os semivariogramas mostraram-se eficientes em agrupar variáveis correlacionadas entre si. Com exceção dos dois atributos de solo sem dependência espacial, a amostragem ao acaso pode levar a erros e alterar resultados de pesquisas, uma vez que a variação existente na área deve ser considerada na análise.

\section{AGRADECIMENTOS E APRESENTAÇÃO}

Os autores agradecem ao Conselho Nacional de Desenvolvimento Científico e Tecnológico (CNPq) (Projeto PRONEX), pela concessão de recursos financeiros e pela concessão de bolsa de produtividade em pesquisa (PQ) aos pesquisadores José Miguel Reichert e Dalvan José Reinert.

Parte da Dissertação de Mestrado de Thelmo Araújo Dariva, apresentada ao Programa de Pós-graduação em Agronomia da Universidade Federal de Santa Maria (UFSM).

\section{REFERÊNCIAS}

ABREU Jr., C.H. et al. Relações entre acidez e propriedades químicas de solos brasileiros. Scient Agric, v.60, p.337-343, 2003.

ABREU, S.L. et al. Variabilidade espacial de propriedades físicohídricas do solo e da produtividade e qualidade de grãos de trigo agroecológico em argissolo franco arenoso sob plantio direto. Cienc Rural, v.33, p.275-282, 2003.

ALBUQUERQUE, J.A. et al. Variabilidade de solo e planta em Podzólico Vermelho-Amarelo. R Bras Ci Solo, v.20, p.151157, 1996.

BOYER, D.G. et al. Soil spatial relationships in a steeply sloping acid soil environment. Soil Sci, v.161, p.278-287, 1996.

BRADFORD, J.M. Penetrability. In: KLUTE, A. (Ed.). Methods of soil analysis: physical and mineralogical properties. Madison: American Society of Agronomy, 1986. p.463-478.

CAMBARDELLA, C.A. et al. Field-scale variability of soil properties in central Iowa soils. Soil Sci Soc Am J, v.58, p.1501-1511, 1994.

CAMPOS, M.C.C. et al. Relações solo-paisagem em uma litosseqüência arenito-basalto na região de Pereira Barreto, SP. R Bras Ci Solo, v.31, p.519-529, 2007.

CORÁ, J.E.; BERALDO, J.M.G. Variabilidade espacial de atributos do solo antes e após calagem e fosfatagem em doses variadas na cultura de cana-de-açúcar. Eng Agríc, v.26, p.374387, 2006.
COUTO, E.G. et al. Estimativa do teor de argila e do potássio trocável em solos esparsamente amostrados no Sul do Estado de Mato Grosso. R Bras Ci Solo, v.24, p.129-140, 2000.

COUTO, E.G. et al. Large area variability of soil chemical properties in central Brasil. Agric Ecosys Environ, v.66, p.139152, 1997

da SILVA, A.P. et al. Variabilidade espacial da resistência a penetração de um latossolo vermelho-escuro ao longo de uma transeção. R Bras Ci Solo, v.13, p.1-5, 1989.

DARIVA, T.A. Variabilidade espacial de solo e da cultura da soja em várzea sistematizada. 2001. 120f. Dissertação (Mestrado em Agronomia) - Universidade Federal de Santa Maria.

DAY, P.R. Particle fractionation and particle-size analysis. In: BLACK, C.A. (Ed.). Methods of soil analysis: physical and mineralogical properties. Madison: American Society of Agronomy, 1965. p.545-567.

EMPRESA BRASILEIRA DE PESQUISA AGROPECUÁRIA EMBRAPA. Serviço Nacional de Levantamento e Conservação do Solo. Manual de métodos de análise de solo. 2.ed. Rio de Janeiro: EMBRAPA, 1997. 212p.

EMPRESA BRASILEIRA DE PESQUISA AGROPECUÁRIA EMBRAPA. Sistema brasileiro de classificação de solos. Brasília: EMBRAPA, 1999. 412p.

GAMMA DESIGN SOFTWARE. Geoestatistics for the environmental sciences (version 5.1 for windows). Michigan: Gamma, 2001. 152p.

GUADAGNIM, C.A. Infiltração de água ao de uma transeção em solos construídos na área de mineração de carvão de candiota - RS. 2002. 62f. Dissertação (Mestrado em Agronomia) - Universidade Federal de Pelotas.

INSTITUTO RIOGRANDESE DO ARROZ - IRGA. Arroz irrigado: recomendações técnicas da pesquisa para o sul do Brasil. 3.ed. Cachoeirinha: Instituto Riograndense do Arroz, 1996. 88p.

JAYNES, D.B.; COLVIN, T.S. Spatiotemporal variability of corn and soybean yield. Agron J, v.89, p.30-37, 1997.

JOURNEL, A.G.; HUIJBEREGTS, Ch.J. Mining geostatistics. Suffolk: Academic, 1989. 600p.

KLEPKER, D.; ANGHINONI, I. Características físicas e químicas do solo, afetadas por métodos de preparo e modos de adubação. R Bras Ci Solo, v.19, p.395-401, 1995.

LEITZKE, V.W. Armazenagem e disponibilidade de água de solos construídos na área de mineração de carvão de Candiota - RS. 2002. 131f. Dissertação (Mestrado em Agronomia) - Universidade Federal de Pelotas.

MATTIAS, J.L. Levantamento detalhado de solos da área experimental do departamento de solos da UFSM e delimitação da superfície da mudança textural abrupta. 1996. 91f. Dissertação (Mestrado em Agronomia) Universidade Federal de Santa Maria. 
MOREnO, J.A. Clima do Rio Grande do Sul. Porto Alegre: Secretaria da Agricultura, Diretoria de Terras e Colonização, Secção de Geografia, 1961. 46p.

NUNES, M.L. et al. Características de solos sistematizados em duas áreas cultivadas com arroz sob inundação. R Bras Ci Solo, v.26, p.395-406, 2002.

OLIVEIRA, J.J. et al. Variabilidade espacial de propriedades químicas em um solo salino-sódico. R Bras Ci Solo, v.23, p.783-789, 1999.

PAVAN, M.A. Alumínio em solos ácidos do Paraná: relação entre o alumínio não-trocável, trocável e solúvel, com o pH, CTC, porcentagem de saturação de Al e matéria orgânica. R Bras Ci Solo, v.7, p.39-46, 1983.

PAZ-GONZÁLEZ, A. et al. The effect of cultivation on the spatial variability of selected properties of an umbric horizon. Geoderma, v.97, p.272-292, 2000.

PREVE, R.E.; MARTENS, D.C. Potential effect of land-leveling on soil fertility in a Brazilian rice soil. Plant Soil, v.121, p.148-150, 1990.

RIBEIRO JÚNIOR, P.J. Métodos geoestatísticos no estudo da variabilidade espacial de parâmetros do solo. 1995. Dissertação (Mestrado em Ciência do Solo) - Escola Superior de Agricultura “Luiz de Queiroz”, USP.

SALVIANO, A.A.C. et al. Variabilidade espacial de atributos de solo e de Crotalaria juncea L. em área severamente erodida. $\mathbf{R}$ Bras Ci Solo, v.22, p.115-122, 1998.

SANTOS, H.L.; VASCONCELOS, C.A. Determinação do número de amostras de solo para análise química em diferentes condições de manejo. R Bras Ci Solo, v.11, p.97-100, 1987.

SAS Institute. SAS User's guide. 5.ed. Cary, N.C., 1996. 956p.

SCHLINDWEIN, J.A.; ANGHINONI, I. Variabilidade horizontal de atributos de fertilidade e amostragem do solo no sistema de plantio direto. R Bras Ci Solo, v.24, p.85-91, 2000.

SILVA, V.R. et al. Variabilidade espacial das características químicas do solo e produtividade de milho em parcelas experimentais em um Argissolo. R Bras Ci Solo, v.34, p.399406, 2004.

SILVEIRA, P.M. et al. Amostragem e variabilidade espacial de características químicas de um latossolo submetido a diferentes sistemas de preparo. Pesq Agrop Bras, v.35, p.2057-2064, 2000 .

SOUZA, C.K. et al. Influência do relevo e erosão na variabilidade espacial de um latossolo em Jaboticabal (SP). R Bras Ci Solo, v.27, p.1067-1074, 2003.

SOUZA, Z.M. de et al. Small relief shape variations influence spatial variability of soil chemical attributes. Sci Agric, v.63, p.161-168. 2006.

SOUZA, Z.M. et al. Variabilidade espacial do $\mathrm{pH}$, Ca, Mg e V\% do solo em diferentes formas do relevo sob cultivo de cana-deaçúcar. Cienc Rural, v.34, p.1763-1771, 2004.

TEDESCO, M.J. et al. Análise de solo, plantas e outros materiais. 2.ed. Porto Alegre: Universidade Federal do Rio Grande do Sul, 1995. 147p. (Boletim Técnico, 5).

THOMAS, G.W.; HARGROVE, W.L. The chemistry of soil acidity. In: ADAMS, F. (ed.) Soil acidity and liming. Madison: American Society of Agronomy, 1984. p.3-56.

TREVISAN, V. Avaliação dos atributos físicos de um complexo de solos hidromórficos sob diferentes sistemas de manejo. 2005. 114f. Dissertação (Mestrado em Agronomia) - Universidade Federal de Pelotas.

TSEGAYE, T.; HILL, R.L. Intensive tillage effects on spatial variability of soil test, plant growth, and nutrient uptake measurements. Soil Sci, v.163, p.155-165, 1998.

VIEIRA, S.R. Geoestatística em estudos de variabilidade espacial do solo. In: NOVAIS, R.F. et al. (Eds). Tópicos em ciência do solo. Viçosa: Sociedade Brasileira de Ciência do Solo, 2000. p.1-54.

VIEIRA, S.R. Geoestatística em estudos de variabilidade espacial. Curso de atualização em conservação de solos. Campinas: Instituto Agronômico de Campinas, 1995. 61p. (Apostila).

VIEIRA, S.R. Variabilidade espacial de argila, silte e atributos químicos em uma parcela experimental de um Latossolo Roxo de Campinas (SP). Bragantia, v.56, p.181-190, 1997.

VIEIRA, S.R.; LOMBARDI NETO, F. Variabilidade espacial do potencial de erosão das chuvas do estado de São Paulo. Bragantia, v.54, p.405-412, 1995.

ZHANG, R. et al. Estimation of the spatial distribution of soil chemicals using pseudo-cross-variograms. Soil Sci Soc Am J, v.56, p.1444-1452, 1992. 